\title{
DESAIN DAN ANALISIS TEGANGAN STRUKTUR CRANE KAPASITAS 10 TON MENGGUNAKAN METODE ELEMEN HINGGA
}

\author{
Lasinta Ari Nendra Wibawa
}

\author{
Pascasarjana Teknik Mesin, Fakultas Teknik, Universitas Sebelas Maret, Surakarta \\ Balai Uji Teknologi dan Pengamatan Antariksa dan Atmosfer Garut, Lembaga Penerbangan dan Antariksa Nasional \\ (LAPAN), Garut \\ Email: lasinta.ari@lapan.go.id
}

Masuk: 16-01-2020, revisi: 10-08-2020, diterima untuk diterbitkan: 10-08-2020

\begin{abstract}
ABSTRAK
Crane merupakan salah satu alat berat yang banyak digunakan dalam suatu industri. Crane berfungsi sebagai alat untuk mengangkat beban berat dan memindahkannya dari satu tempat ke tempat lain secara vertikal maupun horisontal. Di LAPAN Garut, Crane digunakan untuk proses perakitan roket. Penelitian ini meneliti tentang perancangan dan analisis tegangan von Mises struktur Crane dengan kapasitas 10 Ton menggunakan material mild steel. Analisis dilakukan secara numerik dengan menggunakan perangkat lunak Autodesk Inventor Professional 2017. Hasil simulasi menunjukkan struktur Crane memiliki tegangan von Mises, deformasi, massa, dan factor keamanan berturut-turut sebesar 63,73 $\mathrm{MPa} ; 2,173 \mathrm{~mm} ; 1.508,53 \mathrm{~kg}$; dan 3,25.
\end{abstract}

Kata Kunci: autodesk inventor 2017; metode elemen hingga; mild steel; analisis tegangan; tegangan von Mises

\begin{abstract}
Crane is one of the heavy equipment that is widely used in the industry. The crane functions as a tool for lifting heavy loads and moving them from one place to another vertically and horizontally. In the LAPAN Garut office, it is used for the rocket assembly process. The study investigates the design and analysis of von Mises stress of crane structure with a capacity of 10 tons using mild steel material. The investigation was carried out numerically using Autodesk Inventor Professional 2017. The simulation results showed the Crane structure had a von Mises stress, deformation, mass, and safety factor respectively $63.73 \mathrm{MPa} ; 2,173 \mathrm{~mm} ; 1.508,53 \mathrm{~kg}$; and 3.25 .
\end{abstract}

Keywords: autodesk inventor 2017; finite element method; mild steel; stress analysis; von Mises stress

\section{PENDAHULUAN}

Crane merupakan salah satu alat berat yang banyak digunakan dalam suatu industri (Wibawa, 2019d). Crane berfungsi sebagai alat untuk mengangkat beban berat dan memindahkannya dari satu tempat ke tempat lain secara vertikal maupun horisontal. Crane sebagian besar digunakan dalam bidang transportasi, konstruksi, dan industri manufaktur (Khan et al., 2017). Overhead crane, gantry crane, tower crane, mobile crane, dan jib crane adalah beberapa jenis crane yang biasa digunakan di berbagai industri.

Struktur crane dapat mengalami kegagalan karena beberapa faktor. Tegangan bending, deformasi plastik karena beban yang berlebihan, kurangnya perawatan (maintenance), korosi, dan fatik adalah beberapa penyebab kegagalan struktur crane. Struktur crane harus dirancang sesuai dengan kapasitas angkat yang diinginkan agar tidak mengalami kegagalan.

Balai Uji Teknologi dan Pengamatan Antariksa dan Atmosfer Garut atau LAPAN Garut merupakan kantor instansi pemerintah yang melayani kegiatan uji statik dan uji terbang roket. Crane sering digunakan untuk merakit (assembling) komponen-komponen roket (Wibawa, 2019a). Desain struktur crane yang tepat dapat menunjang tugas-tugas di kantor LAPAN Garut. 
Penelitian ini menggunakan material mild steel untuk membuat desain struktur crane dengan kapasitas angkat 10 Ton yang kuat, kokoh, dan ekonomis. Salah satu keunggulan material mild steel yaitu kaku, kuat, mudah dibentuk, pangsa pasar tinggi, dan banyak digunakan di berbagai aplikasi khususnya dalam bidang konstruksi. Material mild steel juga memiliki kekuatan luluh (yield strength) yang relatif tinggi sehingga dapat digunakan untuk mengangkat beban dengan kapasitas yang cukup besar.

\section{METODE PENELITIAN}

Material yang digunakan untuk struktur Crane adalah material mild steel. Penjelasan detail mengenai standar dan ukuran material dapat dilihat pada Gambar 1 dan Tabel 1.

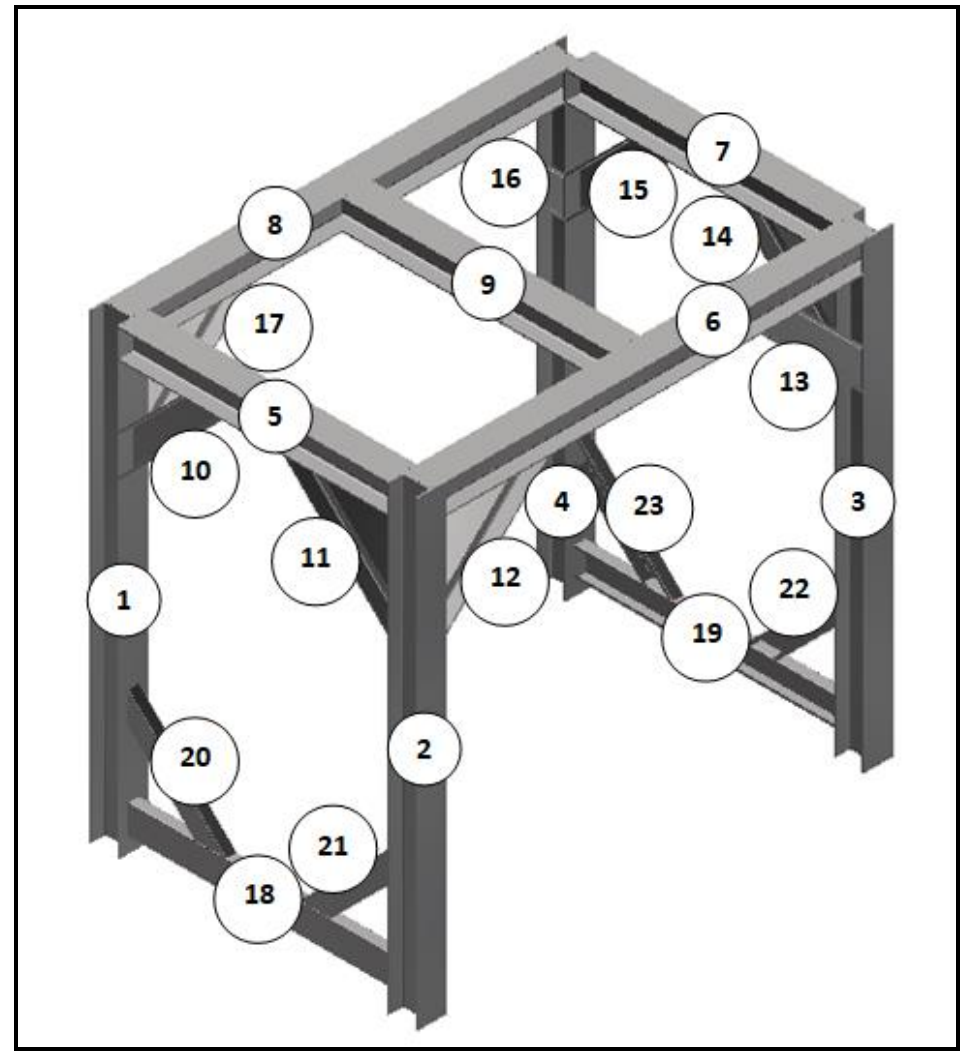

Gambar 1. Desain 3D struktur Crane

Tabel 1. Standar dan ukuran rangka dari sruktur Crane

\begin{tabular}{|c|c|c|}
\hline Keterangan & Standar & Ukuran (mm) \\
\hline Rangka 1 s/d 17 & JIS A 5526 & $200 \times 200 \times 8$ \\
\hline Rangka 18 dan 19 & JIS 4565 & $200 \times 75 \times 25$ \\
\hline Rangka $20 \mathrm{~s} / \mathrm{d} 23$ & JIS 4495 & $150 \times 75 \times 25$ \\
\hline
\end{tabular}

Analisis tegangan pada penelitian ini menggunakan perangkat lunak Autodesk Inventor Professional 2017. Autodesk Inventor merupakan salah satu perangkat lunak pemodelan 3D yang merupakan salah satu produk dari Autodesk Inc. (Wibawa, 2018a). Perangkat lunak pemodelan 3D memudahkan dalam menentukan luas dan volume suatu desain, meskipun desainnya sangat kompleks dan rumit (Wibawa, 2019b). Hal ini memudahkan dalam menghitung kebutuhan komponen. 
Autodesk Inventor menggunakan metode elemen hingga untuk melakukan analisis tegangan (Wibawa, 2019g). Analisis elemen hingga merupakan analisis numerik komputer yang digunakan untuk menyelesaikan masalah kompleks di banyak bidang Sains dan Teknik, khususnya pada mekanika padat (solid mechanics) dengan membagi obyek menjadi bentuk jala (mesh). Variabel dari elemen yang tidak diketahui adalah nilai perpindahan untuk setiap titik node (Gerdemeli \& Kurt, 2014). Metode elemen hingga umum digunakan dalam analisis tegangan pada struktur Crane (Imran \& Kadir, 2017). Analisis struktur teknik dapat berupa analisis tegangan maupun analisis getaran.

Penelitian ini menggunakan analisis tegangan statik. Analisis tegangan statik merupakan analisis yang paling umum digunakan dalam bidang rekayasa teknik, termasuk dalam bidang desain Crane (Reddy, et. al., 2016)(Ramamurthi, et. al., 2019)(Xu, et. al., 2017)(Zeng, et. al., 2012). Analisis statik merupakan jenis analisis struktural yang paling umum digunakan dalam metode elemen hingga (Kolte, et. al., 2017)(Liu, et. al., 2014). Tegangan, deformasi, dan faktor keamanan dari suatu komponen dapat diselidiki dalam berbagai kondisi beban untuk memastikan bahwa kegagalan dapat dihindari pada tahap desain (Wibawa, 2020).

Proses simulasi tegangan menggunakan software Autodesk Inventor ada beberapa tahap: Pertama, membuat desain rangka struktur Crane. Desain meliputi bentuk dan dimensi dari struktur Crane. Dimensi struktur Crane ditunjukkan pada Gambar 2.

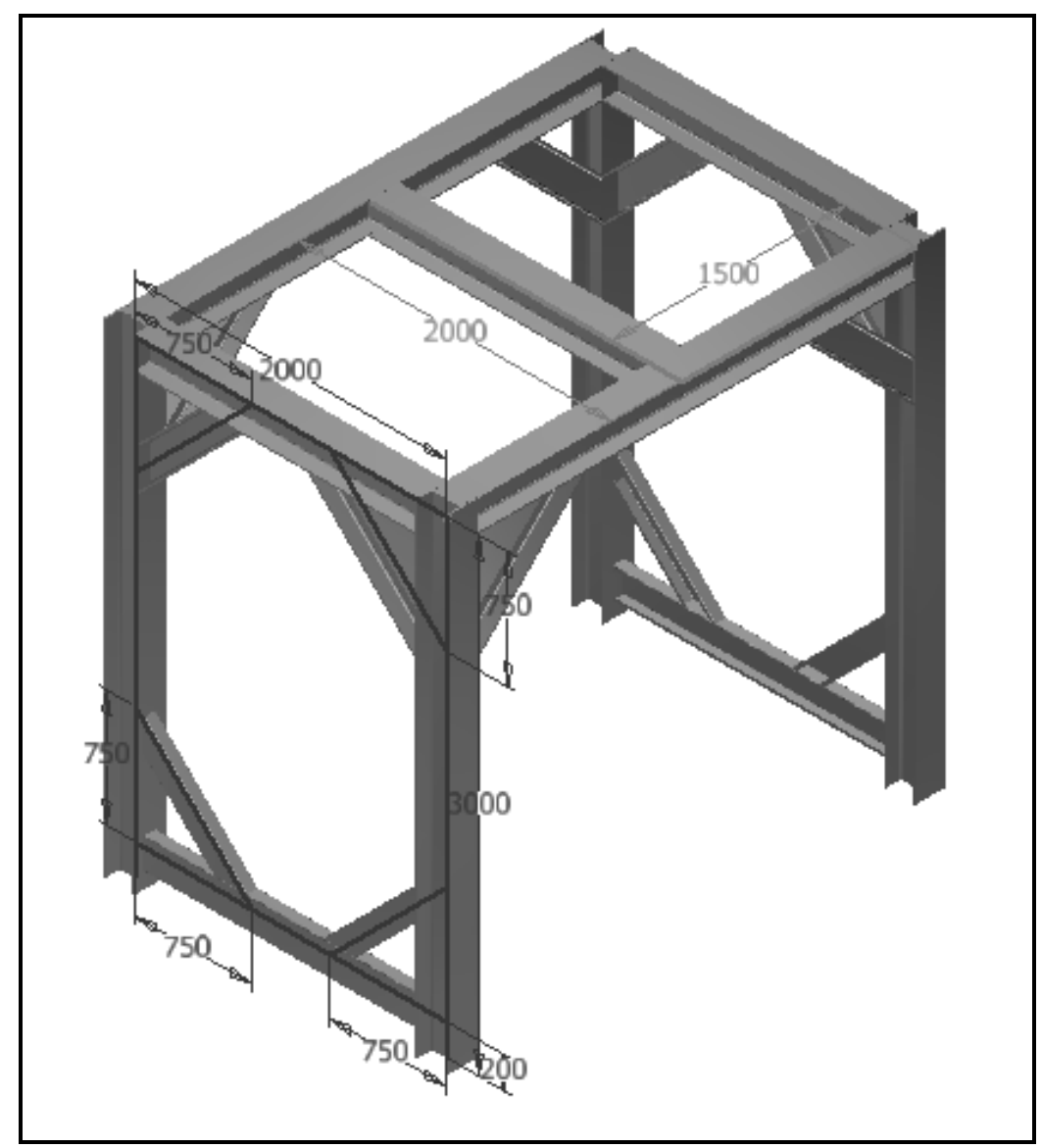

Gambar 2. Dimensi struktur Crane kapasitas 10 ton (dalam mm) 
Kedua, menentukan jenis material yang digunakan. Material yang dipilih adalah mild steel yang merupakan material yang mudah didapatkan di pasaran. Standar rangka yang digunakan pada analisis rangka (frame analylis) Autodesk Inventor adalah 17 batang rangka JIS A 5526, 2 batang rangka JIS 4565, dan 4 batang rangka JIS 4495.

Ketiga, menentukan batasan (constraint). Batasan yang digunakan adalah fixed constraint pada 4 (empat) kaki struktur Crane.

Keempat, menentukan besarnya beban. Beban yang digunakan adalah 10 Ton (10.000 kg) sehingga jika dinyatakan dalam satuan Newton $(\mathrm{N})$ menjadi $98.100 \mathrm{~N}$.

Kelima, menjalankan proses meshing. Simulasi ini menggunakan jenis kontak terikat (bonded contact) antar sambungan struktur. Simulasi kontak terikat mensimulasikan ikatan permukaan yang kaku satu sama lain. Kontak terikat termasuk sambungan las (welding) atau perekat (glue) antara dua bagian. Proses meshing pada simulasi ini membagi komponen menjadi 151.273 node dan 74.258 elemen seperti ditunjukkan pada Gambar 3.

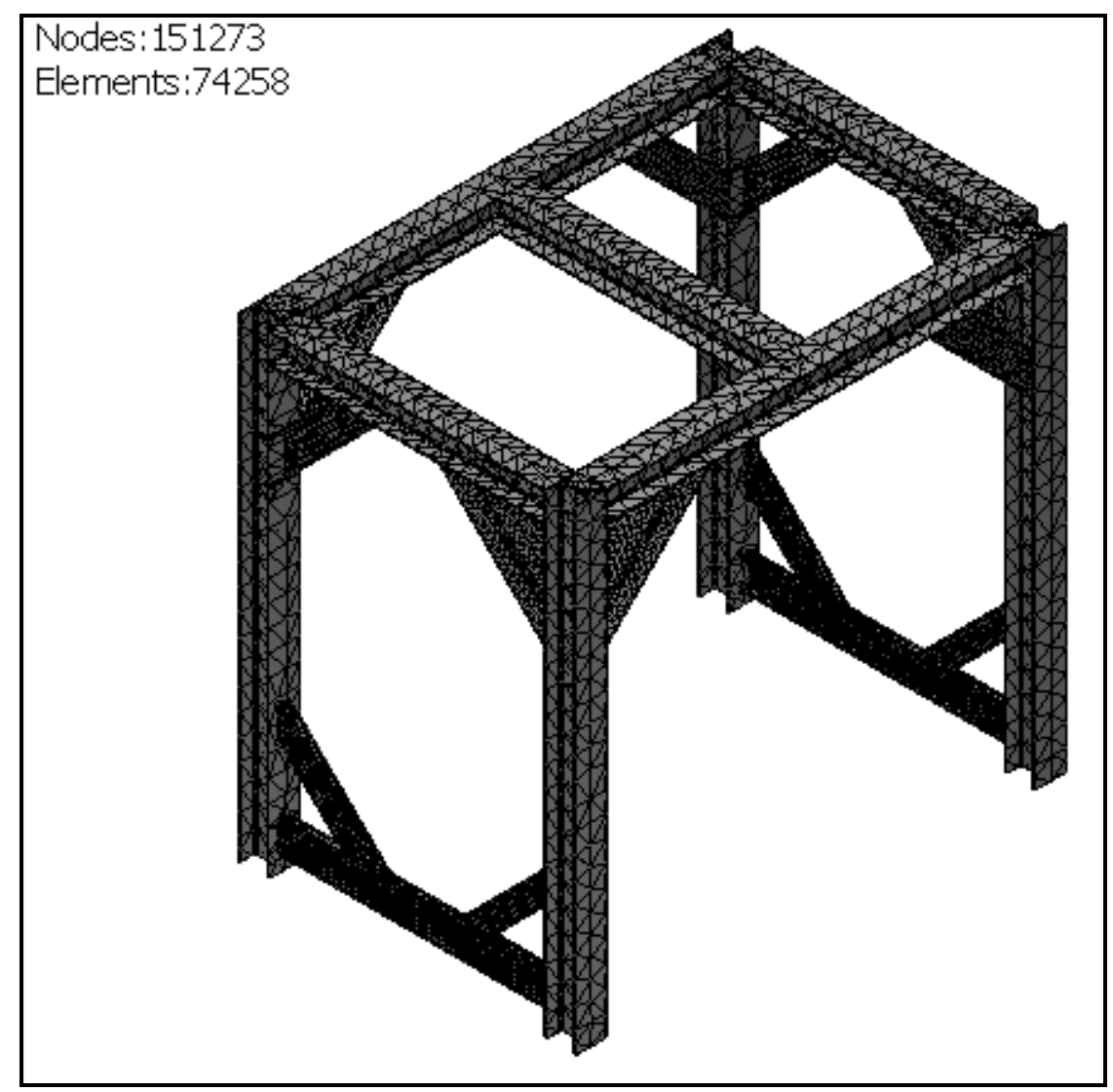

Gambar 3. Proses meshing struktur Crane

Keenam, menjalankan simulasi tegangan statik. Simulasi tegangan Autodesk Inventor akan menghasilkan tegangan von Mises, deformasi, massa, dan faktor keamanan (Wibawa, 2019c). Simulasi juga akan menampilkan titik-titik kritis dari desain yang telah dibuat.

Kondisi batas (boundary condition) pada analisis tegangan menggunakan Autodesk Inventor Professional 2017 dapat dilihat dari Tabel 2 berikut ini. 
Tabel 2. Kondisi batas (boundary condition) analisis tegangan

\begin{tabular}{cc}
\hline Parameter & Keterangan \\
\hline Tipe simulasi & Single Point \\
\hline Kapasitas & 10 Ton $(10.000 \mathrm{~kg})$ \\
\hline Percepatan gravitasi & $9,81 \mathrm{~m} / \mathrm{s}^{2}$ \\
\hline Total muatan & $98.100 \mathrm{~N}$ \\
\hline Average element size & $0,2 \mathrm{~mm}$ \\
\hline Minimum element size & $0,1 \mathrm{~mm}$ \\
\hline Safety Factor & Berdasarkan yield strength \\
\hline Jumlah node & 151273 \\
\hline Jumlah elemen & 74258
\end{tabular}

Asumsi pada saat melakukan analisis tegangan Asumsi pada saat melakukan analisis tegangan statik menggunakan perangkat lunak Autodesk Inventor, yaitu (Wibawa, 2018b):

a. Sifat material mild steel tetap linier setelah batas luluh.

b. Deformasi material mild steel sangat kecil dibandingkan ukuran komponen secara keseluruhan.

c. Material bersifat kaku dan ulet. Misalnya, material logam.

d. Hubungan setiap rangka diasumsikan kontak berikat (bonded contact). Artinya, permukaan antar rangka kaku satu sama lain. Kontak ini dapat berupa sambungan las atau adhesif.

\section{HASIL DAN PEMBAHASAN}

Tabel 3 menunjukkan sifat fisik material mild steel. Material mild steel memiliki densitas sebesar $7,85 \mathrm{gram} / \mathrm{cm}^{3}$. Hal ini berdampak pada massa total struktur Crane seberat $1.581,53 \mathrm{~kg}$.

Tabel 3. Sifat fisik material mild steel

\begin{tabular}{cc}
\hline Material & Mild Steel \\
\hline Density & $7,85 \mathrm{~g} / \mathrm{cm}^{3}$ \\
\hline Mass & $1.581,53 \mathrm{~kg}$ \\
\hline Area & $40572300 \mathrm{~mm}^{2}$ \\
\hline Volume & $201469000 \mathrm{~mm}^{3}$ \\
\hline Center of Gravity & $\mathrm{x}=191,62 \mathrm{~mm}$ \\
& $\mathrm{y}=591,96 \mathrm{~mm}$ \\
& $\mathrm{z}=11,21 \mathrm{~mm}$ \\
\hline Yield Strength & $207 \mathrm{MPa}$ \\
\hline Young's Modulus & $345 \mathrm{MPa}$ \\
\hline Poisson's Ratio & $220 \mathrm{GPa}$ \\
\hline Shear Modulus & $0,275 \mathrm{ul}$ \\
\hline
\end{tabular}

Hasil simulasi Autodesk Inventor menggunakaan analisis statik linier. Analisis statik merupakan metode untuk menentukan tegangan pada komponen yang mengalami beban statis maupun dinamis (Younis, 2010). Analisis statik bertujuan untuk memastikan struktur atau komponen dapat dengan aman menahan beban yang telah ditentukan. Kondisi ini dapat tercapai saat tegangan yang dihasilkan kurang dari kekuatan luluh material dalam menahan beban. Hubungan tegangan ini disebut sebagai faktor keamanan. 
Teori tegangan maksimum menyatakan bahwa kegagalan terjadi saat tegangan utama maksimum suatu struktur mencapai nilai tegangan maksimum pada batas elastis. Teori ini biasa digunakan untuk memprediksi kegagalan material getas. Namun, pada benda elastis yang berlaku beban tiga dimensi, tegangan kompleks terjadi. Hal ini berarti bahwa pada setiap titik di dalam benda ada tekanan yang bekerja dalam berbagai arah (Wibawa, 2018b). Teori energi distorsi maksimum (von Mises) menghitung apakah kombinasi tegangan pada titik tertentu akan menyebabkan kegagalan (Wibawa, 2018b). Teori von Mises menyatakan bahwa material ulet mengalami luluh saat invarian kedua tegangan deviatorik mencapai nilai kritis (Wibawa, 2019e). Teori von Mises merupakan teori plastisitas yang berlaku paling baik untuk material ulet, terutama logam (Wibawa, 2019e).

Gambar 4 menunjukkan hasil simulasi struktur Crane terhadap beban 98.100 N. Tegangan von Mises maksimal sebesar 63,73 MPa. Tegangan von Mises masih berada di bawah kekuatan luluh (yield strength) material mild steel, yaitu sebesar $207 \mathrm{MPa}$.

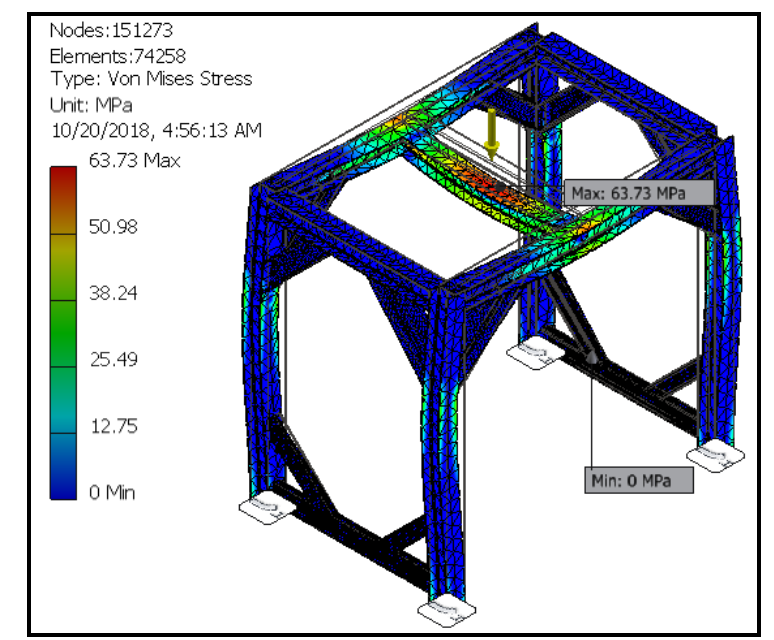

Gambar 4. Tegangan von Mises struktur Crane dengan beban 98.100 N.

Deformasi merupakan proses perubahan bentuk atau distorsi pada suatu komponen yang terjadi akibat adanya beban. Deformasi menjadi salah satu indikator untuk mengetahui kekuatan material. Nilai deformasi yang semakin kecil menunjukkan semakin kuat suatu material, sedangkan nilai deformasi yang semakin besar menunjukkan semakin lemah suatu material. Nilai deformasi maksimal pada penelitian ini relatif sangat kecil, yaitu 2,7271 mm (Gambar 5).

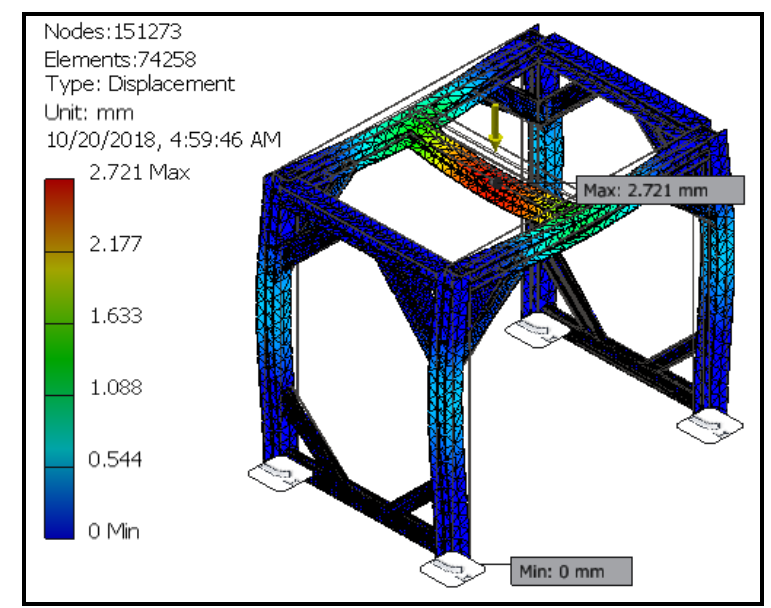

Gambar 5. Deformasi struktur Crane dengan beban 98.100 N. 
Faktor keamanan (safety factor) menyatakan seberapa kuat suatu sistem dibanding yang dibutuhkan sistem tersebut untuk beban yang diinginkan. Faktor keamanan minimum menggunakan simulasi Autodesk Inventor dihitung sebagai kekuatan luluh dari material yang dibagi dengan tegangan von Mises maksimum (Wibawa, 2019f). Faktor keamanan didesain jauh lebih kuat dari yang dibutuhkan untuk penggunaan normal bertujuan untuk memastikan keamanan saat terjadi beban tak terduga, cacat pada material, dan memperpanjang umur fatik. Faktor keamanan kurang dari 1 (satu) menunjukkan kegagalan dari suatu desain (Wibawa, et. al., 2019).

Hasil simulasi secara umum menunjukkan rancangan struktur Crane masih cukup aman untuk menahan beban 10 Ton atau $98.100 \mathrm{~N}$. Hal ini karena nilai faktor keamanan minimumnya sebesar 3,25 (Gambar 6). Nilai ini lebih tinggi dari standar minimal yang dipersyaratkan untuk suatu komponen atau struktur mampu menahan beban dinamis. Beban dinamis adalah beban yang dapat terjadi atau bekerja secara tiba-tiba pada suatu komponen atau struktur. Beban dinamis biasanya kecil, tetapi berubah-ubah terhadap waktu. Beban dinamis perlu diantisipasi karena struktur Crane sering mengalami beban fluktuatif dari beban yang diangkatnya. Rentang nilai faktor keamanan yang dipersyaratkan untuk struktur mampu menahan beban dinamis yaitu sekitar 2-3 (Dobrovolsky, et. al., 1978).

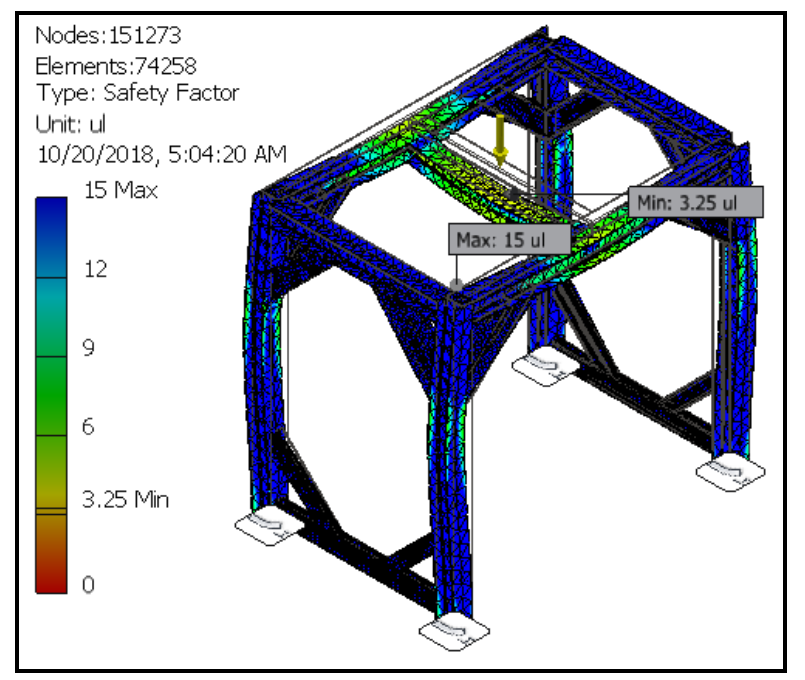

Gambar 6. Faktor keamanan struktur Crane dengan beban 98.100 N.

\section{KESIMPULAN}

a. Desain struktur Crane menggunakan material mild steel memiliki massa sebesar $1.581,53 \mathrm{~kg}$.

b. Pada pembebanan 10 Ton atau $98.100 \mathrm{~N}$, struktur Crane memiliki tegangan von Mises maksimum sebesar 63,73 MPa. Nilai tegangan ini masih jauh di bawah kekuatan luluh (yield strength) material mild steel, yaitu $207 \mathrm{MPa}$.

c. Pada pembebanan 10 Ton atau $98.100 \mathrm{~N}$, struktur Crane memiliki nilai deformasi maksimum sebesar 2,721 mm. Nilai deformasi ini menunjukkan struktur Crane cukup kokoh untuk menahan beban 10 Ton.

d. Pada pembebanan 10 Ton atau 98.100 N, struktur Crane memiliki nilai faktor keamanan sebesar 3,25. Nilai ini menunjukkan desain dari struktur Crane sangat aman untuk menahan beban dinamis. 


\section{REFERENSI}

Dobrovolsky, V., \& Zablonsky, K. (1978). Machine elements : a textbook. Moscow: Peace Publisher.

Gerdemeli, I., \& Kurt, S. (2014). Design and finite element analysis of gantry crane. Key Engineering Materials, 572(1), 517-520.

Imran, A. I., \& Kadir. (2017). Simulasi Tegangan Von Mises Dan Analisa Safety Factor Gantry Crane Kapasitas 3 Ton. DINAMIKA Jurnal Ilmiah Teknik Mesin, 8(2), 1-4. Retrieved from http://ojs.uho.ac.id/index.php/dinamika/article/view/2378

Khan, E. R., Kardile, V. S., Dhakane, P. D., Gore, A. P., \& Mahajan, B. D. (2017). Design And Analysis of Crane Hook with Different Materials. International Journal of Innovative and Emerging Research in Engineering, 4(3), 7.

Kolte, S. S., Bhagat, S. R., Danke, V. H., \& Mundhe, V. K. (2017). Comparitive Study Of Design Process Using Analytical Method And FEM. International Journal of Modern Trends in Engineering \& Research, 4(6), 1-6. https://doi.org/10.21884/ijmter.2017.4175.oxkkj

Liu, P. F., Xing, L. J., Liu, Y. L., \& Zheng, J. Y. (2014). Strength analysis and optimal design for main girder of double-trolley overhead traveling crane using finite element method. Journal of Failure Analysis and Prevention, 14(1), 76-86. https://doi.org/10.1007/s11668-0139767-1

Ramamurthi, M. S., \& Nagababu, B. N. (2019). Modeling And Analysis Of Gantry Crane With Different Materials. International Journal of Scientific Development and Research (IJSDR), 4(1), 229-239.

Reddy, M. A., \& Krishnaveni, M. N. V. (2016). Modelling and Analysis of Double Girder Gantry Crane. International Journal of Engineering and Management Research, 6(4), 181184.

Wibawa, L. A. N. (2018a). Merancang Komponen Roket 3D dengan Autodesk Inventor Professional 2017. Buku Katta.

Wibawa, L. A. N. (2018b). Simulasi Kekuatan Komponen Sarana Pengujian Roket Menggunakan Autodesk Inventor Professional 2017. Buku Katta.

Wibawa, L. A. N. (2019a). Desain dan Analisis Kekuatan Dudukan (Bracket) AC Outdoor Menggunakan Metode Elemen Hingga. Jurnal Crankshaft, 2(1), 19-24. https://doi.org/10.24176/crankshaft.v2i1.2688

Wibawa, L. A. N. (2019b). Desain dan Analisis Kekuatan Rangka Lemari Perkakas di Balai LAPAN Garut Menggunakan Metode Elemen Hingga. Machine: Jurnal Teknik Mesin, 5(2), 45-50. https://doi.org/doi.org/10.33019/jm.v5i2.787

Wibawa, L. A. N. (2019c). Desain dan Analisis Tegangan Alat Pengangkat Roket Kapasitas 10 Ton Menggunakan Metode Elemen Hingga. Jurnal Energi Dan Teknologi Manufaktur (JETM), 02(01), 23-26.

Wibawa, L. A. N. (2019d). Desain dan Simulasi Elemen Hingga Gantry Crane Kapasitas 9 Ton Menggunakan Autodesk Inventor 2017. Manutech: Jurnal Teknologi Manufaktur, 11(02), 41-48.

Wibawa, L. A. N. (2019e). Pengaruh Kecepatan Landing Vertikal Terhadap Ketahanan Beban Impak Rangka Landing Gear Menggunakan Metode Elemen Hingga. Angkasa: Jurnal Ilmiah Bidang Teknologi, 11(1), 35-42. https://doi.org/10.28989/angkasa.v11i1.434

Wibawa, L. A. N. (2019f). Pengaruh Pemilihan Material Terhadap Kekuatan Rangka Main Landing Gear Untuk Pesawat UAV. Jurnal Teknologi Dan Terapan Bisnis, 2(1), 48-52.

Wibawa, L. A. N. (2019g). Pengaruh Susunan dan Jumlah Lubang Baut Terhadap Kekuatan Rangka Main Landing Gear Untuk Pesawat UAV. Flywheel, 5(1), 46-50.

Wibawa, L. A. N. (2020). The Fatigue Life Prediction of Gantry Crane with Load Capacity 
Variation using Ansys Workbench. Teknika: Jurnal Sains Dan Teknologi, 16(1), 18-24. https://doi.org/10.36055/tjst.v16i1.7490

Wibawa, L. A. N., \& Diharjo, K. (2019). Desain, Pemilihan Material, dan Faktor Keamanan Stasiun Pengisian Gawai Menggunakan Metode Elemen Hingga. Jurnal Teknologi, 11(2), 97-102.

Xu, G., Tao, Y., \& Liu, W. (2017). Research on U type gantry crane structure parametric finite element analysis system based on C\# and APDL. 113(Ifmca 2016), 611-618. https://doi.org/10.2991/ifmca-16.2017.95

Younis, W. (2010). Up and running with Autodesk Inventor Simulation 2011: a step-by-step guide to engineering design solutions. Elsevier.

Zeng, Q. D., \& Guan, B. H. (2012). Modal finite element analysis of reconstructive structure for gantry crane on the basis of ANSYS and dynamic stiffness. Applied Mechanics and Materials, 164, 456-459. https://doi.org/10.4028/www.scientific.net/AMM.164.456 
DESAIN DAN ANALISIS TEGANGAN STRUKTUR CRANE

KAPASITAS 10 TON MENGGUNAKAN METODE ELEMEN HINGGA 